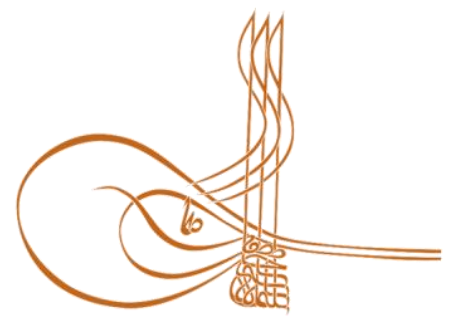

www.turkishstudies.net/economy
Turkish Studies - Economics, Finance, Politics

eISSN: 2667-5625

Research Article / Araştırma Makalesi

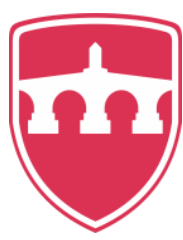

INTERNATIONAL BALKAN

UNIVERSITY

Sponsored by IBU

\title{
Hata Türü ve Etkileri Analizi Yönteminde Hata Türlerinin Veri Zarflama Analizi ile Önceliklendirilmesi
}

\author{
Prioritisation of Failure Modes By Data Envelopment Analysis in Failure Mode and Effect \\ Analysis Method
}

Muhammed Maruf*

\begin{abstract}
The failure mode and effect analysis method (FMEA) is a method of risk evaluation which is widely used in a large number of industries and has been subjected to numerous scientific researches and applications. Prioritization of the failure modes in the method is carried out according to the risk priority number as the risk priority indicator. The risk priority number is obtained by multiplying the three risk assessment factors values that express the probability of occurence the failure (Occurence), the customer impact level of the failure (Severity) and the likelihood that the failure will be detected before the product or service reaches the customer (Detectability). The method is intensely criticized in the literature about the calculation of the Risk Priority Number (RPN) value which calculated for the purpose of prioritizing failure modes. In addition, the costs of the preventive actions that need to be made after prioritizing the failure modes are ignored in the implementation of the method. In today's conditions, where costs related to products and services become very important for enterprises, ignoring costs related to preventive actions poses a disadvantage for the applicability of the method. In order to eliminate these disadvantages, an approach is presented in which the failure modes are prioritized by the data envelopment analysis method and the costs of the preventive actions for eliminating the failure modes are also taken into account. Thus, a methodology was applied which provided a more proper result in both prioritization of the failure modes, and it was possible to obtain more applicable results by taking into account the costs of the recovery. İn consequence of the study, the results of prioritization of failure modes according to RPN value and the proposed method were compared.
\end{abstract}

Structured Abstract: Failure mode and effect analysis is a method applied to identify and eliminate potential failure modes. In this method, it is aimed to identify the failures that may ocur in a product or process and to prevent the poor quality at the beginning. In addition, this method enables the definition of design and process characteristics and to shed light on areas where required improvement in process control. Failure mode and effect analysis has become a widely used method because it enables the identification of failures in products and processes and eliminating them with preventive actions. In the method, the failure

\footnotetext{
* Dr. Öğr. Üyesi, Kırşehir Ahi Evran Üniversitesi, İktisadi ve İdari Bilimler Fakültesi, İşletme Bölümü Asst. Prof. Dr., Kirsehir Ahi Evran University, Faculty of Economics and Administrative Sciences ORCID 0000-0002-5388-639X drahmetmaruf@gmail.com

Cite as/ Atıf: Maruf, M. (2020). Hata türü ve etkileri analizi yönteminde hata türlerinin veri zarflama analizi ile önceliklendirilmesi, Turkish Studies - Economy, 15(1), 323-332. https://dx.doi.org/10.29228/TurkishStudies.39330

Received/Geliş: 17 October/Ekim 2019

Checked by plagiarism software

Accepted/Kabul: 25 March/Mart 2020

Published/Yayın: 30 March/Mart 2020

Copyright (C) INTAC LTD, Turkey

CC BY-NC 4.0
} 
modes are prioritized according to the Risk Priority Number value which obtained by multiplying the three risk factor values expressed as Severity (S), Occurence (O) and Detectability (D). Although failure modes and effect analysis method is widely used, it has been criticized in the literature. Some of these critisizm are listed below. Although the effects of different occurence, severity and detectability values on failure risk are different in the method, the multiplication of the values can give the same risk priority number value. For example, a failure mode with severity, occurence, and detectability values respectively of 4, 5, 6 and an another failure mode of 6,10 and 2 would have same risk priority number as 120 . Such a stuation, there is no clear solution for which failure mode is given priority in this method. The formula for determining the risk priority number value is also debatable and there is no explanation as to why the risk factors (Severity, Occurence and Detectability) values are multiplied. Since the risk priority number value is obtained by multiplying three risk factors, it is very sensitive to small changes in risk factor values. For example, severity, occurence and detectability risk factor values are 9, 9 and 10, respectively, while the risk priority number value is 810 , severity, occurence and detectability risk factor values are 9, 10 and 10, respectively, the risk priority number value is 900 . Another disadvantage of the method is that the costs of preventive actions to be taken after the prioritization of the failure are not taken into account in the ranking of the failure modes. Costs related to product or service have gained great importance in current competition conditions. Ignoring the improvement costs in determining the priority values of the failure modes is an important deficiency in terms of the applicability of the method. In industrial applications, it is not possible for enterprises to ignore the costs of preventive actions. Therefore, considering prevention costs as one of the priority factors in order of failure modes will provide more realistic results.

In this study, the failure modes which experienced in a wooden door production process were prioritized by data envelopment analysis method. By using data envelopment analysis method in order to sort the failure modes, the disadvantages related to the calculation of the risk priority number value were eliminated. Furthermore, the costs of the preventive actions to eliminate the failures were taken into account in determining the priority values. Thus, it is aimed to eliminate the disadvantages of the failure modes and effect analysis method which mentioned in the literature. The high value of the risk factors in the failure mode and effect analysis method indicates that the failure mode is prior in terms of prevention activities to be performed. Therefore, failure modes which have higher risk factor values will be prioritized in terms of prevention activities. Thus, risk factor values are considered as output variables in data envelopment analysis method. Costs of prevention activities to eliminate the failures are considered as input variables.

As a result of using data envelopment analysis to prioritize failure modes, a different order was obtained according to the ranking made by the risk priority number value. In the ranking made according to the value of risk priority number, the problem of swelling at the doors appeared as the first priority failure modes, while Massive doors turning problem took the first place with the data envelopment analysis taking into account the costs of preventive activities. Other failure modes have different sort values in the prioritization process with both methods. The results obtained by classical failure mode and effect analysis method and the ranking values obtained by data envelopment analysis method which considering the prevention costs.are quite different from each other. According to the results obtained by using data envelopment analysis method, failure modes with high risk factor values relatively and lower costs for preventive activities were found to be the prior.

Keywords: Failure Mode and Effect Analysis, Risk Assessment, Relative Efficiency Analysis

Jel Codes: M11, L15

Öz: Hata türü ve etkileri analizi yöntemi (Failure Mode And Effect Analysis, FMEA), çok sayıda endüstri dalında yaygın bir şekilde kullanılan ve üzerinde çok sayıda bilimsel araştırma ve uygulama yapılan bir hata önceliklendirme yöntemidir. Yöntemde, belirlenen hataların önceliklendirilmesi risk önceliği göstergesi olarak ifade edilen öncelik değerlerine göre gerçekleştirilmektedir. Risk önceliği göstergesi (Risk Priority Number, RPN) değeri, hatanın ortaya çıkma olasılığı (Olasılık), hatanın müşteri etkileme düzeyi (Şiddet) ve hatanın ürün veya hizmet müşteriye ulaşmadan önce tespit edilebilirliğini (Keşfedilebilirlik) ifade eden üç risk değerlendirme faktörünün çarpılması ile elde edilmektedir. Yöntem hataların önceliklendirilmesi amacıyla hesaplanan söz konusu RPN değerinin hesaplanması konusunda literatürde yoğun bir şekilde eleştiri almaktadır. Ayrıca yöntemin uygulanmasında hata türlerinin önceliklendirme işleminden sonra yapılması gereken önleyici işlemlerin maliyetleri göz ardı edilmektedir. Ürün ve hizmete ilişkin maliyetlerin

Turkish Studies - Economy, 15(1) 
işletmeler açısından çok büyük önem kazandığı günümüz koşullarında önleyici işlemlere ilişkin maliyetlerin göz ardı edilmesi yöntemin uygulanabilirliği açısından dezavantaj oluşturmaktadır. Söz konusu dezavantajların ortadan kaldırılması amacıyla, bu çalışmada hata türlerinin veri zarflama analizi yöntemine ile sıralandığı ve hata türlerinin ortadan kaldırılmasına yönelik önleyici işlemlerin maliyetlerinin de hesaba katıldığı bir yaklaşım sunulmuştur. Böylece hem hata türlerinin önceliklendirilmesinde daha uygun sonuç veren bir metodoloji uygulanmış, hem de iyileştirme maliyetleri de hesaba katılarak daha uygulanabilir sonuçların elde edilmesi mümkün olmuştur. Çalışma sonucunda hata türlerinin RPN değerine göre ve önerilen yönteme göre önceliklendirilmesine ilişkin sonuçlar karşılaştırılmıştır.

Anahtar Kelimeler: Hata Türü ve Etkileri Analizi, Risk Değerlendirme, Göreli Etkinlik Analizi

Jel Kodu: M11, L15

\section{Giriş}

Hata türü ve etkileri analizi bir süreç, tasarım, sistem ve hizmet için olası hata türlerinin belirlenmesi, önceliklendirilmesi ve önleyici faaliyetlerle ortadan kaldırılması yada azaltılmasını amaçlayan bir risk değerlendirme yöntemidir. Hata türü ve etkileri analizi yönteminde belirlenen hata türleri risk önceliği göstergesi (RÖG) olarak ifade edilen ve risk değerlendirme faktörlerinin çarpımından elde edilen bir önceliklendirme değeri ile sıralanmaktadır. Hata türü ve etkileri analizi yöntemi farklı uygulama dezavantajları nedeniyle eleştirilere konu olmaktadır. Yönteme ilişkin en önemli dezavantajlardan birisi hata türlerinin ortadan kaldırılması için uygulanacak önleme faaliyetlerine ilişkin maliyetlerin, hataların öncelik değerlerine göre sıralanmasında hesaba katılmamasıdır. Ayrıca, hata türlerinin RÖG değerine göre önceliklendirilmesi konusundaki dezavantajları nedeniyle eleştirilmektedir. Literatürde yer alan farklı çalışmalarda söz konusu dezavantajların ortadan kaldırılması amacıyla hata türü ve etkileri analizi yöntemi farklı yöntemlerle birlikte uygulanmıştır.

Chin ve diğerleri (2009) hata türlerinin sıralanması için, hata türü ve etkileri analizi yöntemi ile veri zarflama analizi yöntemini kullanmıştır. Ancak söz konusu çalışmada bu çalışmadan farklı olarak hata önleme maliyetleri hata türlerinin önceliklendirilmesinde hesaba katılmamıştır. Al Tahat ve diğerleri (2012) hata türü ve etkileri analizinde hata türlerinin önceliklendirilmesi için sıralı lojistik regresyon modeli uygulamıştır. Liu ve diğerleri (2012) hata türü ve etkileri analizi ve bulanık VIKOR yönteminin birlikte uygulandığı bir model ortaya koymuştur. Vencheh ve diğerleri (2013) hataların önceliklendirilmesi amaciyla hata türü ve etkileri analizi ile bulanık doğrusal programlama modelinin birlikte kullanıdlığı bir çalışma yapmıştır. Maheswaran ve Loganathan (2013) hata türlerinin önceliklendirilmesi amaciyla hata türü ve etkileri analizi, analitik hiyerarşi süreci ve PROMETHEE yöntemlerinin birlikte uygulandığı bir risk değerlendirme modeli ortaya koymuştur. Baynal ve diğerleri (2018) hata türlerinin önceliklendirilmesinde hata türü ve etkileri analizi ile gri ilişkisel analiz yöntemlerini birlikte kullanmıştır. Chang ve diğerleri (2019) hata türlerinin sıralanması amaciyla TOPSIS ve DEMATEL yöntemlerinin birlikte uygulandığı bir çalışma yapmıştır.

$\mathrm{Bu}$ çalışmada hata türlerinin önceliklendirilmesinde her bir hata türü için belirlenen iyileştirme faaliyetlerinin maliyetlerinin de hesaba katıldığ bir yaklaşım sunulmuştur. Ayrıca hata türlerinin önceliklendirilmesine yönelik literatürde yer alan dezavantajların ortadan kaldırılması amacıyla veri zarflama analizi yöntemi kullanılmıştır. Hata türlerinin hesaplanmasında kullanılan önceliklendirme değerleri veri zarflama analizi yöntemi ile hesaplanarak elde edilen sonuçlara göre hata türleri sıralanmıştır. Uygulanan veri zarflama analizi modelinde hata türü ve etkileri analizi yönteminde kullanılan risk faktör (Olasılık, Şiddet ve Keşfedilebilirlik) değerleri çıktı değişken, hataların ortadan kaldırılmasına ilişkin önleme faaliyetlerine ilişkin maliyet değerleri ise girdi değişken olarak ele alınmıştır. Ayrıca çalışma sonunda risk önceliği göstergesi değerine göre yapılan sıralama ve veri zarflama analizi yöntemi ile elde edilen sıralama karşılaştırılmış ve sonuçlar değerlendirilmiştir. 


\section{Hata Türü ve Etkileri Analizi}

Hata türü ve etkileri analizi, potansiyel hata türlerinin değerlendirilmesi ve önlenmesi amacıyla uygulanan bir analiz yöntemidir. Bu yöntemde, "Ne yanlış gidebilir?" ve "Herhangi bir şey yanlış giderse sonuçları ne olur?" soruları yanıtlanarak, tasarım aşamasında süreçlerde ortaya çıkabilecek hataların belirlemesi ve kalitesizliğin daha başlangıçta önlenmesi amaçlanmaktadır. Ayrıca bu yöntem, tasarım ve süreç karakteristiklerinin tanımlanması ile süreç kontrolünde iyileştirme yapılması gereken alanlara 1şık tutulmasını da sağlar (Sofyalığlu 2011:1). Diğer risk analiz yöntemlerinden farklı olarak Hata türü ve etkileri analizi, sistemde var olan hataların belirlenmesi ile birlikte, oluşması muhtemel hataların tespit edilmesine yönelik proaktif bir yaklaşım da içerir (Liu ve diğerleri 2012:1). Bu amaçla uygulanan Hata türü ve etkileri analizi sistem güvenilirliği çalışmalarında yaygın kullanılan etkili bir hata önleme metodolojisidir. FMEA Amerika, Japonya ve Avrupa'da endüstri ve akademide çok geniş bir uygulama alanı bulmuştur (Chen ve Lee 2007: 1). Literatürde sistem HTEA, servis HTEA, tasarım HTEA ve süreç HTEA olmak üzere dört farklı Hata türü ve etkileri analizi yöntemi yer almaktadır.

Her bir hata türü 1-10 arası değer alan üç risk faktörüne göre değerlendirilir. Bu risk faktörleri; şiddet (Ş), olasılık (O) ve tespit edilebilirlik (T) olarak ifade edilmektedir. Şiddet, belirlenen hata türlerinin sistemi ve müşteriyi etkileme derecesi olarak ifade edilmektedir. Olasılık, belirlenen hata türlerinin ortaya çıkma sıklığını ifade etmektedir. Keşfedilebilirlik ise belirlenen hata türlerinin ürün müşteriye ulaşmadan ve müşteriyi etkilenmeden tespit edilebilirliğini ifade etmektedir. En yüksek risk önceliğine sahip hata türlerinin belirlenmesi söz konusu üç risk faktörünün aldığı değerlerin çarpılması ile elde edilen RÖG değerlerinin sıralanması ile gerçekleştirilir (Kutlu ve Ekmekçioğlu 2012: 1).

$$
\mathrm{RÖG}=0 \times S ̧ \times \mathrm{T}
$$

$\mathrm{Bu}$ üç risk faktörünün alabileceği değerlerin olumludan, olumsuza doğru sıralaması Tablo 1 de verilmiştir (Öztekin 2006: 45)

Tablo 1: Olasılık - Şiddet - Tespit Edilebilirlik Değer Aralıkları

\begin{tabular}{|c|c|c|}
\hline \multirow{2}{*}{ Olasilık } & \multicolumn{2}{|c|}{12345678910} \\
\hline & Neredeyse İmkansız & Neredeyse Kaçınılmaz \\
\hline Şiddet & Etkisi Yok & Çok Tehlikeli Etki \\
\hline Keşfedilebilirlik & Neredeyse Kesin & Tespit Edilemez \\
\hline
\end{tabular}

Tablo 1'de görüldüğü gibi olasılık değerinin "1" olması hatanın ortaya çıkmasının neredeyse imkansız olduğunu, 10 olması ise hatanın muhtemel her tekrarda ortaya çıktığını göstermektedir. Şiddet değerinin "1" olması hatanın müşterinin ürüne ilişkin algısını etkilemediğini, 10 olması ise müşteri algısını çok yüksek derecede etkilediğini göstermektedir. Keşfedilebilirlik değerinin 1 olması hatanın ürün/hizmet müşteriye sunulmadan belirlenme olasılığının çok yüksek olduğunu, 10 olması ise müşteriye sunulmadan tespit edilmesi olasılığının çok düşük olduğunu ifade etmektedir.

Hata türü ve etkileri analizi yöntemi geniş uygulama alanı bulan bir yöntem olmasına rağmen, literatürde farklı eleştirilere maruz kalmıştır. Yöntemde farklı olasılık, şiddet ve keşfedilebilirlik değerlerinin hata riski üzerindeki etkilerinin birbirinden farklı olmasına rağmen, değerlerin çarpımı aynı RÖG değerini verebilmektedir. Örnek olarak sırasıyla şiddet, olasılık ve tespit edilebilirlik değerleri 4, 5, 6 olan bir hata türü ile 6,10 ve 2 olan bir hata türünün RÖG değeri her ikisi için 120 olarak bulunacaktır. Bu durumda hangi hata türüne öncelik verileceğine ilişkin net bir çözüm yoktur. RÖG değerinin belirlenmesi ile ilgili formül tartışmaya açıktır. Risk faktörlerinin aldığı değerlerin neden çarpıldığ 1 ile ilgili net bir açıklama yoktur (Chin 2009: 1). RÖG değeri risk faktörlerinin çarpımı ile elde edildiği için risk faktörlerinde yaşanan küçük 
değişikliklere karşı çok duyarlıdır (Maheswaran ve Loganathan 2013: 2). Örnek olarak O, Ş ve K risk faktör değerleri sırayla 9, 9 ve 10 iken RÖG değeri 810 olur. $O$, Ş ve $K$ değerleri 9,10 ve 10 olduğu ise 900 olmaktadır. Yönteme ilişkin yukarıda ifade edilen dezavantajların yanı sıra hata türlerinin önceliklendirilmesinden sonra yapılacak, hataları ortadan kaldırmaya yönelik önleyici faaliyetlerin maliyetlerinin önceliklendirmede hesaba katılmaması yöntemin en önemli dezavatajlarından birisidir. Mevcut rekabet koşullarında ürün veya hizmete ilişkin maliyetlerin çok büyük önem kazandığı günümüzde öncelikli olarak iyileştirme faaliyeti yapılacak hata türünün belirlenmesinde iyileştirme maliyetlerinin göz ardı edilmesi, yöntemin uygulanabilirliği açsısından önemli bir eksiktir.

\section{Veri Zarflama Analizi}

Veri zarflama analizi çok sayıda benzer nitelikli girdi ve çıktılar üreten işletme veya organizasyonel birimlerin göreli etkinliğini ölçmek amacıyla kullanılan doğrusal programlama tabanlı bir yöntemdir. (Tütek, Gümüşoğlu ve Özdemir, 2012: 223) Veri zarflama analizi yönteminde farklı ölçüm birimleri ile ölçülen girdi ve çıktılara sahip birimlerin göreli etkinliği ölçümlenebilmektedir. Veri zarflama analizi ile farklı ölçü birimleri ile ifade edilebilen girdi ve çıktılar için etkinlik değeri ölçülebilir. Veri zarflama analizinde önceden belirlenmiş herhangi bir üretim fonksiyonuna gerek kalmadan birimlerin girdi ve çıktı değerleri ile göreli etkinlik analizi yapılabilir (Behdioğlu ve Özcan 2009: 303). Ayrıca yöntem az sayıda varsayıma sahip olduğu için çoklu girdi ve çıktıların karmaşık yapısından dolayı diğer yaklaşımların uygulanamadığı vakalar açısından da etkinlik ölçümü imkanı sağlamaktadır (Cook ve Zhu 2005: 1). Veri zarflama analizi yönteminde organizasyonel birimlerin etkinlik skorları aşağıdaki şekilde elde edilmektedir (Bal 2013: 4).

$$
\text { Etkinlik }=\frac{\text { Ağırlıklandırılmış Çıktılar Toplamı }}{\text { Ağırlıklandırımış Girdiler Toplamı }}
$$

Tüm etkinlik skorları "0" ile "1" arasında değer alır. Düşük skor düşük etkinlik anlamına gelir. Etkinlik değeri "1"” e eşit olan karar verme birimi etkin kabul edilir (Kelly ve diğerleri 2012: 65). Veri zarflama analizi en etkin birimin etkinlik değerini baz alarak bir etkinlik sınırı belirler. Belirlenen etkinlik sınırının üstünde değere sahip karar verme birimleri etkin olarak kabul edilir. Veri zarflama analizinde etkin olan karar verme birimleri, etkin olmayanlar için referans olarak belirlenebilir. Referans karar verme birimleri etkin olamayanlar için girdi ve çıktı değerleri bakımından hedef değerleri ortaya koyar (Korhonen 1997:1). Veri zarflama modelleri sabit girdi ile en yüksek çıktıyı alma varsayımı olarak uygulandığında oluşturulan model "Çıktı odaklı" olarak ifade edilir. En az girdi ile belirli bir çıktıyı elde etme varsayımı ile uygulandığı zaman oluşturulan model "Girdi odaklı" şeklinde ifade edilir (Günay 2015: 18).

Veri zarflama analizinin temel özellikleri ve avantajları aşağıdaki şekilde sıralanabilir. Veri zarflama analizi ile farklı ölçü birimleri ile ifade edilebilen girdi ve çıktılar için etkinlik değeri ölçülebilir. Veri zarflama analizi ile etkinlik sonuçları ağırlık değerleri ile manipüle edilmeden etkinlik değerleri hesaplanabilir (Tütek ve diğerleri 2012: 225). Parametrik olmayan bir yöntem olmasından dolayı önceden belirlenmiş herhangi bir üretim fonksiyonuna gerek kalmadan birimlerin girdi ve çıktı değerleri ile göreli etkinlik analizi yapılabilir (Behdioğlu ve Özcan 2009: 303). Ayrıca yöntem az sayıda varsayıma sahip olduğu için çoklu girdi ve çıtıların kompleks yapısından dolayı diğer yaklaşımların uygulanamadığı vakalar açısından da etkinlik ölçümü imkanı sağlamaktadır (Cook ve Zhu 2005: 1).

Veri zarflama analizi literatüründe "CCR modeli", "BCC modeli", "Toplamsal model" ve "Aylak tabanlı model" gibi çok sayıda model vardır. Bu çalışmada uygulanacak olan CCR model, organizasyonel birimlerin göreli etkinliğini ölçeğe göre sabit getiri varsayımı ile ölçmek amacıyla Charnes, Cooper ve Rhodes tarafindan 1978 yilında ortaya konan veri zarflama analizi modelidir. (Behdioğlu ve Özcan 2009: 305). CCR model çoklu bir fonksiyon formundadır ancak birçok girdi 
ve birçok çıktıyı tek bir virtüel çıktıya indirgeyen bir modeldir (Kutlar ve Babacan, 2008: 151). Bu çalışmada kullanılacak olan girdi odaklı CCR model aşağıdaki şekilde oluşturulur (Tütek ve diğerleri 2012: 233).

Amaç Fonksiyonu:

$$
\text { Maks } \eta_{k}=\sum_{r=1}^{s} \mu_{r} y_{r k}
$$

Kisitlar:

$$
\begin{aligned}
& \sum_{i=1}^{m} w_{i} x_{i k}=1 \\
& \sum_{r=1}^{s} \mu_{r} y_{r j}-\sum_{i=1}^{m} w_{i} x_{i j} \leq 0 \quad(j=1 \ldots . n) \\
& \mu_{r}, w_{i} \geq \varepsilon>0 \quad(r=1 \ldots . . s) \text { ve }(i=1 \ldots . m)
\end{aligned}
$$

Yukarıdaki formülde yer alan;

$\mu_{r}$ : r. çıktının ağırlık değerini,

$y_{r k}:$ r. karar verme biriminin k. çıktı değerini,

$w_{i}$ : i. girdinin ağırlık değerini,

$x_{i k}:$ i. karar verme biriminin k. girdi değerini ifade etmektedir.

\section{Uygulama}

$\mathrm{Bu}$ çalışmada hata türlerinin veri zarflama analizi yöntemi ile sıralandığı ve öncelik değerlerinin hesaplanmasında hatalara ilişkin önleme faaliyetlerinin maliyetlerinin hesaba katıldığ 1 bir model sunulmuştur. Hata türlerinin veri zarflama analizi ile önceliklendirilmesi amaciyla Ankara'da faaliyet gösteren bir ahşap kapı üretim tesisinde panel kapı üretim sürecinde uygulama gerçekleştirilmiştir. Söz konusu ahşap kapı üretim sürecinde ortaya çıkan hata türleri, hata türlerine iliş̧in olasılık, şiddet ve keşfadilebilirlik risk faktörü değerleri ve hataların ortadan kaldırılması için yapılacak önleme faaliyetlerine ilişkin öngörülen maliyet değerleri Tablo 2'de verilmiştir.

Tablo 2: Ahşap Kapı Üretiminde Hata Türleri, Risk Faktör ve Maliyet Değerleri

\begin{tabular}{|l|c|c|c|l|c|}
\hline HATA TÜRLERI & O & Ş & K & \multicolumn{1}{|c|}{ ÖNLEM } & MALIYET \\
\hline Kaplamada kabarma & 5 & 9 & 5 & Tutkallama makinesi alınması & 12.000 \\
\hline $\begin{array}{l}\text { Renk tonunun } \\
\text { ayarlanamaması }\end{array}$ & 5 & 8 & 4 & Otomatik boya makinası alınması & 25.000 \\
\hline $\begin{array}{l}\text { Masif/Gürgen kapılarda } \\
\text { dönme sorunu }\end{array}$ & 3 & 7 & 6 & $\begin{array}{l}\text { Doğal yollarla kurutma ve çift } \\
\text { firnnlama }\end{array}$ & 6.000 \\
\hline Kapı kasa uyumsuzluğu & 3 & 7 & 5 & Kasa ebatlama makinası & 20.000 \\
\hline $\begin{array}{l}\text { Kapı kolu/kilit yerinin } \\
\text { yanlış ayarlanması }\end{array}$ & 3 & 7 & 2 & $\begin{array}{l}\text { Bilgisayarlı kapı kolu/kilit açma } \\
\text { makinası alınması }\end{array}$ & 11.000 \\
\hline
\end{tabular}

Kap1 üretim sürecinde karşılaşılan ilk hata türü kapılarda kabarma sorunudur. Sorunun kaynağı tutkalın doğru ve eşit şekilde yayılmaması, ortamın tozlu olması olarak belirlenmiştir. Ortadan kaldırılması için temiz/tozsuz ortamda tutkallama makinesi kullanımı önerilmiştir. İkinci hata türü renk tonunun tutturulamaması sorunudur. Çözüm için manuel boyama yerine renk koduna 
göre boya karışımını otomatik olarak ayarlayan boya makinesinin kullanılması önerilmiştir. Üçüncü hata türü Masif/gürgen kapılarda dönme sorunudur. Gürgen içindeki sıvıyı zor atan bir üründür. Dolayısıyla bir defa firınlama ile kurumamakta, kurumaması da daha sonra şekil değişimine neden olmaktadır. Bu nedenle birinci firınlamadan sonra gürgen malzemenin doğal kurumaya bırakılması ve sonra ikinci firınlamaya tabi tutulması önerilmektedir. Dördüncü hata türü ise kapı kasa uyumsuzluğunun yaşanmasıdır. Hatanın önlenmesi için kasanın bütün olarak ebatlanmasını sağlayan kasa ebatlama makinesine geçiş düşünülmüş. Belirlenen son hata türü ise kapı kilit yerinin yanlış açılmasıdır. Farklı kilit türlerine göre kapı kilit yerinin büyüklüğü ve yeri değişmektedir. Bu hatanın önlenmesi için ise kilit türüne göre kilit yerini otomatik olarak açan kapı kolu/kilit açma makinasının kullanımı önerilmiştir. Bu bilgiler 1şığında ilk olarak klasik FMEA yöntemine göre olasılık, şiddet ve keşfedilebilirlik değerlerinin çarpılması ile tüm hata türleri için RPN değerleri hesaplanmış ve hata türlerinin sıralaması yapılmıştır. Tablo 3'de hata türlerinin RPN değerleri ve bu değerlere göre sıralama değerleri yer almaktadır.

Tablo 3: Hata Türleri RPN Değerleri ve Sıralaması

\begin{tabular}{|l|r|r|r|c|c|}
\hline HATA TÜRLERI & O & Ş & K & RÖG DEĞERI & SIRALAMA \\
\hline Kaplamada kabarma & 5 & 9 & 5 & 225 & 1 \\
\hline Renk tonunun ayarlanamaması & 5 & 8 & 4 & 160 & 2 \\
\hline Masif/Gürgen kapılarda dönme sorunu & 3 & 7 & 6 & 126 & 3 \\
\hline Kapı kasa uyumsuzluğu & 3 & 7 & 5 & 105 & 4 \\
\hline Kapı kolu/kilit yerinin yanlış ayarlanması & 3 & 7 & 2 & 42 & 5 \\
\hline
\end{tabular}

Hata türlerinin sıralanması amacıyla veri zarflama analizi yöntemi kullanılarak hem RÖG değerinin hesaplanması ile ilgili dezavantajların ortadan kaldırılması, hem de hataların ortadan kaldırılmasına ilişkin önlemlerin maliyetleri öncelik değerlerinin belirlenmesinde hesaba katılmıştır. Böylece hata türü ve etkileri analizi yöntemine ilişkin literatürde yer verilen dezavantajların ortadan kaldırılması amaçlanmıştır. Hata türü ve etkileri analizi yönteminde hataların önceliklendirilmesinde kullanılan risk faktörlerinin (Olasılık, Şiddet ve Keşfedilebilirlik) aldığ 1 değerlerin yüksek olması söz konusu hata türünün yapılacak önleme faaliyetleri bakımından öncelikli olduğunu göstermektedir. Dolayısıyla daha yüksek risk faktörü değerine sahip olan hata türleri önleme faaliyetleri bakımından öncelikli olarak ele alınacaktır. Bu nedenle risk faktörü değerleri veri zarflama analizi için çıktı değişken olarak ele alınmıştır. Hataların ortadan kaldırılması için yapılacak önleme faaliyetlerinin maliyetleri ise girdi değişken olarak ele alınmıştır. Hata türlerinin veri zarflama analizi ile önceliklendirilmesinde önleme maliyetleri belirleyici olacağı için belirli bir çıktıyı en az girdi ile elde etmeyi hedefleyen girdi odaklı CCR model kullanılması uygun görülmüsstür. Bu çerçevede ilk hata türü olan "Kapılarda kabarma" hatası için girdi odaklı CCR model aşağıdaki gibi oluşturulur.

Amaç Fonksiyonu:

$$
\text { Max }=5 \mu_{1}+9 \mu_{2}+5 \mu_{3}
$$

Kisitlar:

$$
\begin{aligned}
& 12.000 w_{1}=1 \\
& 5 \mu_{1}+9 \mu_{2}+5 \mu_{3}-12.000 w_{1} \leq 0 \\
& 5 \mu_{1}+8 \mu_{2}+4 \mu_{3}-25.000 w_{1} \leq 0 \\
& 3 \mu_{1}+7 \mu_{2}+6 \mu_{3}-6.000 w_{1} \leq 0 \\
& 3 \mu_{1}+7 \mu_{2}+5 \mu_{3}-20.000 w_{1} \leq 0
\end{aligned}
$$




$$
\begin{aligned}
& 3 \mu_{1}+7 \mu_{2}+2 \mu_{3}-11.000 w_{1} \leq 0 \\
& \mu_{r}, w_{i} \geq \varepsilon>0 \quad(r=1 \ldots .3) \text { ve }(i=1)
\end{aligned}
$$

Tüm hata türleri için veri zarflama analizi modeli ayrı ayrı oluşturulur. Kurulan veri zarflama analizi modellerinde sadece amaç fonksiyonu ve birinci kısıt değişir diğer kısıtlar ise aynı kalır. Veri zarflama analizi modeli ile yapılan göreli etkinlik analizi sonuçlarına göre hata türlerinin etkinlik değerleri ve sıralamaları Tablo 4'de verilmiştir. Tablo 4'de ayrıca hata türü ve etkileri analizi yöntemine göre, olasılık, şiddet ve keşfedilebilirlik risk faktörlerinin çarpımı ile elde edilen risk öncelik göstergesi (RÖG) değerlerine göre elde edilen sıralama sonuçları da verilmiştir.

Tablo 4: Hata Türlerinin İki Yönteme Göre Sıralama Değerleri

\begin{tabular}{|l|r|r|r|r|}
\hline \multirow{2}{*}{ HATA TÜRLERİ } & \multicolumn{2}{|c|}{ VZA } & \multicolumn{2}{c|}{ KLASİK HTEA } \\
\cline { 2 - 5 } & ETKİNLIK PUANI & SIRALAMA & RÖG DEĞERİ & SIRALAMA \\
\hline Kaplamada kabarma & 0,833 & 2 & 225 & 1 \\
\hline $\begin{array}{l}\text { Renk tonunun } \\
\text { ayarlanamaması }\end{array}$ & 0,399 & 4 & 160 & 2 \\
\hline $\begin{array}{l}\text { Masif/Gürgen kapılarda } \\
\text { dönme sorunu }\end{array}$ & 1 & 1 & 126 & 3 \\
\hline Kapı kasa uyumsuzluğu & 0,3 & 5 & 106 & 4 \\
\hline $\begin{array}{l}\text { Kapı kolu/kilit yerinin } \\
\text { yanlış ayarlanması }\end{array}$ & 0,545 & 3 & 42 & 5 \\
\hline
\end{tabular}

\section{Sonuç}

Hata türü ve etkileri analizi belirli bir ürün, süreç ve tasarım için mevcut ve/veya olası hata türlerinin belirlenmesi ve önlenmesi amacıyla kullanılan bir risk değerlendirme yöntemidir. Yöntem akademi ve endüstride yaygın olarak kullanılmasına rağmen, hata türlerinin önceliklendirilmesinde kullanılan risk önceliği göstergesi değerinin hesaplanması konusundaki dezavantajlar nedeniyle eleştirilmektedir. Yönteme ilişkin literatürde yer alan eleştirilere ek olarak hata türü ve etkileri analizinin en önemli dezavantajlarından birisi hata türlerinin önceliklendirilmesinde hatalara ilişkin önleme maliyetlerinin göz ardı edilmesidir. Olası hataların ortadan kaldırılması için yapılacak önleme faaliyetleri işletmeler açısından maliyet oluşturabilir. Günümüz rekabet koşullarında maliyetlerin işletmeler açısından çok büyük önem kazandığı bir dönemde hata türlerinin önceliklendirilmesinde önleme maliyetlerinin göz ard1 edilmesi yöntemin uygulanabilirliğini kısıtlayan bir etken olabilir. $\mathrm{Bu}$ nedenle bu çalışmada hata türlerinin önceliklendirilmesinde risk faktörü değerleri ile birlikte önleme maliyetlerinin de göz önüne alındığ bir yaklaşım sunulmuştur. Ahşap kapı üretim sürecinde yaşanan hata türleri veri zarflama analizi yöntemi ile önceliklendirilmiştir.

Hata türlerinin önceliklendirilmesinde önleme maliyetlerinin de sıralamaya etki eden faktörlerden birisi olarak ele alınması sonucunda, risk önceliği göstergesi değerine göre yapılan sıralamaya göre farklı bir sıralama elde edilmiştir. Risk önceliği göstergesi değerine göre yapılan sıralamada "Kapılarda kabarma" sorunu ilk öncelikli hata türü olarak çıkarken, veri zarflama analizi ile, önleyici faaliyetlerin maliyetleri hesaba katılarak yapılan sıralamada "Masif kapılarda dönme sorunu" ilk sırada yer almıştır. Diğer hata türleri de her iki yöntemle yapılan önceliklendirme işleminde farklı sıralama değerlerine sahip olmuştur. Elde edilen sonuçlara göre klasik hata türü veetkileri analizi yöntemi ile elde edilen sıralama ile önleme maliyetleri de göz önüne alınarak veri zarflama analizi yöntemi ile elde edilen sıralama birbirinden farklıdır. Hataların önlenmesine ilişkin önlemlerin maliyetinin hesaba katılması ve hata türlerinin önceliklendirilmesinde risk önceliği göstergesi değeri yerine veri zarflama analizi yöntemi kullanılması farklı sonuçların elde edilmesini sağlamıştır. 
$\mathrm{Bu}$ çalışmada hata türü ve etkileri analizi yönteminde hata türlerinin önceliklendirilmesi için risk önceliği göstergesi değeri yerine veri zarflama analizi yöntemi kullanılarak yönteme ilişkin literatürde yer alan dezavantajların ortadan kaldırılması amaçlanmıştır. Endüstri uygulamalarında işletmelerin yaşanan hataları önem düzeyine göre sıralama ve önleyici faaliyetlerle hataları minimize etmeleri sürecinde önleme faaliyetlerinin maliyetlerini öz ardı etmeleri mümkün değildir. Bu nedenle hata türlerinin sıralanmasında önleme maliyetlerinin de öncelik faktörlerinden birisi olarak ele alınması daha gerçekçi sonuçların alınmasını sağlayacak ve yöntemin uygulanabilirliğini artıracaktır.

\section{Kaynakça}

Akyüz, K. C., Çamur \& G., Yıldırım, İ. (2015), Mobilya ve levha sektöründe veri zarflama analizi yardımı ile etkinlik ölçümü. Türkiye Ormancılık Dergisi, 16(1), 50-59. https://doi.org/10.18182/tjf.91910

Bal, Vedat. (2013), Vakıf Üniversitelerinde Veri Zarflama Analizi ile Etkinlik Belirlenmesi, Manas Sosyal Araştırmalar Dergisi, 2 (1), 1-20.

Behdioğlu, S. \& Özcan G. (2009), "Veri Zarflama Analizi ve Bankacilık Sektöründe Bir Uygulama", Süleyman Demirel Üniversitesi İktisadi ve İdari Bilimler Fakültesi Dergisi, 14(3), 301-326.

Chen, K., J., Lee \& Y., C. (2007), Risk Priority Evaluated by ANP in Failure Mode and Effect Analysis, Quality Tolls and Techniques, 4, 1-6.

Chin, K., S, Wang, M., W., Poon, G., K., K. \& Yang, J., B. (2009), Failure Mode and Effect Analysis by Data Envelopment Analysis, Decision Support Systems, 48 (1), 246-256. https://doi.org/10.1016/j.dss.2009.08.005

Cook, W. D. \& Zhu J. (2005). Modeling Performance Measurement Applications and Implementatioan Issues in DEA. New York. Springer.

Günay, Burhan (2015), BİST'de İșlem Gören KOBİ Gıda İşletmelerinin Veri Zarflama Analizi Yöntemi İle Etkinliklerinin Ölçülmesi, Akademik Bakış Dergisi, 47, 16-34.

Kelly, E., Shalloo, L., Geary, U., Kinsella, A. \& Wallace, M. (2012), Application of data Envelopment Analysis to Measure Technical Efficiency on a Sample of Irish Dairy Farms, Irish Journal of Agricultural and Food Research, 51, 63-77.

Korhonen, P. (1997). Searching the Efficient Frontier in Data Envelopment Analysis. IIASA Interim Reports.

http://citeseerx.ist.psu.edu/viewdoc/download?doi=10.1.1.203.685\&rep=rep1\&type=pdf (19.08.2016).

Kutlu, A., C. ve Ekmekçioğlu, M. (2012), Fuzzy Failure Modes and Effect Analysis by Using Fuzzy TOPSIS-Based Fuzzy AHP, Expert System with Applications, 39, 61-67.

Liu H., C., Liu, L. \& Mao, X., L. (2012), Risk Evaluation in Failure Mode and Effect Analysis with Extended VIKOR Method Under Fuzzy Environment, Expert Systems with Applications, 39, 12926-12934. https://doi.org/10.1016/j.eswa.2012.05.031

Maheswaran, K. \& Loganathan, T. (2013), A Novel Approach for Prioritizaton of Failure Modes in FMEA Using MDCM, International Journal of Engineering Research and Applications, 3(4), 733-739.

Sofyalığlu, Çiğdem (2011), Grey Evaluation Model of Process Failure Mode Effect Analysis, Ege Akademik Bakış, 11(1), 1443-1452. 
Tay M., K. ve Lim C., P. (2006), Fuzzy FMEA with a Guided Rules Reduction System for Prioritization of Failures, Internatioal Journal of Quality \& Reliability Management, 23(8), 1047-1066.

Tütek, H., Gümüşoğlu Ş. \& Özdemir, A. (2012), Sayısal Yöntemler Yönetsel Yaklaşım, Beta Basım Yayım, İstanbul.

Wang Y., M., Chin K., S., Poon, G., K., K. \& Yang, J., B. (2009), Risk Evaluation in Failure Mode and Effect Analysis Using Weighted Geometric Mean, Expert Systems with Applications, 36(2), 1195-1207. 